\title{
ANALYSIS OF PARAMETERS OF THE ENGINE WORKING IN TWO THERMODYNAMIC CYCLES
}

\author{
Mariusz Cygnar \\ State Higher Vocational School in Nowy Sacz \\ Institute of engineering \\ Zamenhofa 1 Street, 33-300 Nowy Sacz, Poland \\ tel.: +48184434545, fax: +48185472609 \\ e-mail:mcygnar@pwsz-ns.edu.pl
}

\begin{abstract}
The article presents an experimental research conducted on a test engine based on a driving unit with a spark ignition Toyota Yaris 1,300 $\mathrm{cm}^{3}$, equipped with two systems of power supply i.e.: fundamental and ignition. Two methods of initiating the combustion process were applied in the engine i.e.: from spark ignition and after it has turned off - the combustion is initiated by means of the injection of the ignition dose. The fundamental task of The adaptation of two power supply systems for a combustion engine is the possibility of work in two thermodynamic circulations, which permits better conditions for creating the fuel-air mixture, which translates directly into significant improvement of the engine's working parameters accuracy, such as general efficiency as well as the individual fuel consumption. The experimental research presented in this work consist of designing and construction of an engine with two injection systems with a controller managing the automatic change of the work mode, as well as the execution of the analysis of the chosen work parameters in a two-cycle engine i.e.:

- comparative research on the engine's work performance, when it works with a spark ignition and when it is initiated with the autoignition of the ignition dose,

- determining the increase in the general efficiency of the two-cycle engine, working with the injection of the ignition dose, in comparison with the conventional power supply system with the initiation of the combustion process from an electric discharge between the spark plug electrodes.

Applying the two-cycle engine with two power supply systems with an automatic spark ignition presented in this article, along with the electronically controlled system of changing the ignition method, increases the general efficiency in the total range of rotational speed, compared with the conventional engines with the automatic spark ignition.
\end{abstract}

Keywords: two cycle engine, two fuel injection systems.

\section{Introduction}

The fast motorization development in the world makes the combustion engines constructors face high requirements as far as the obtained working parameters are concerned, along with the simultaneous reduction of fuel consumption and the capacity of the exhaust fumes toxic components.

The main problem concerning the development of four-stroke combustion engines used in the automotive industry is the still low general efficiency. The huge advancements in electronics enable the application of complex control systems, which, together with the two power supply systems allow obtaining higher values of general efficiency at a lower emission of the toxic exhaust fumes components. Nowadays, the solution implemented to production in the world is the engine with direct multipoint injection, but operating in one thermodynamic circulation with the spark ignition in the total range of loading and rotational speed. This solution was first applied in Lexus IS 350 by Toyota. Nowadays the works on two-cycle engines are conducted by the automobile manufacturers such as Mercedes-Benz and Volkswagen, but due to the narrow range of rotational speed at which regular work is obtained, these works do not satisfy the requirements that new constructions face. 
The fundamental objective of the adaptation of two power supply systems to the combustion engine is to enable the engine to work in two thermodynamic circulations, owing to which it is possible to obtain better conditions to create the fuel-air mixture, which translates directly into significant improvement of the engine working parameters accuracy i.e.: the general efficiency as well as the individual fuel consumption.

\section{Research object and test stand}

To conduct the profound analysis of the work of the two-cycle engine with two injection systems - fundamental (based on spark ignition) and ignition, (the injection of the ignition dose to the engine cylinder follows turning off the spark ignition), an appropriate power supply system was designed and built with the electronic system for automatic change of the work mode, consisting of the fluent transition from the spark ignition to initiating the combustion process from the ignition dose injection (automatic ignition). The adaptation of the constructed additional power supply system to the chosen driving unit [1] enabling an optimum building of an experimental test engine was executed. The systems of the fundamental dose injection were installed in the engine head, in the approach lines before the embranchment of ducts directed to each of the two approach valves of the respective cylinders. For the purpose of enabling the injection of the ignition dose directly to the working space, holes were made in the test engine head, passing through the water casing to the four combustion chambers. Within the holes, thin-walled sleeves were placed, made from stainless steel, in which the high-pressure injection systems of the ignition dose were installed. The sleeves were glued in the holes by means of high-endurance epoxy resin with the filler in the form of aluminium dust. Fig. 1 presents the test stand with the measuring points.

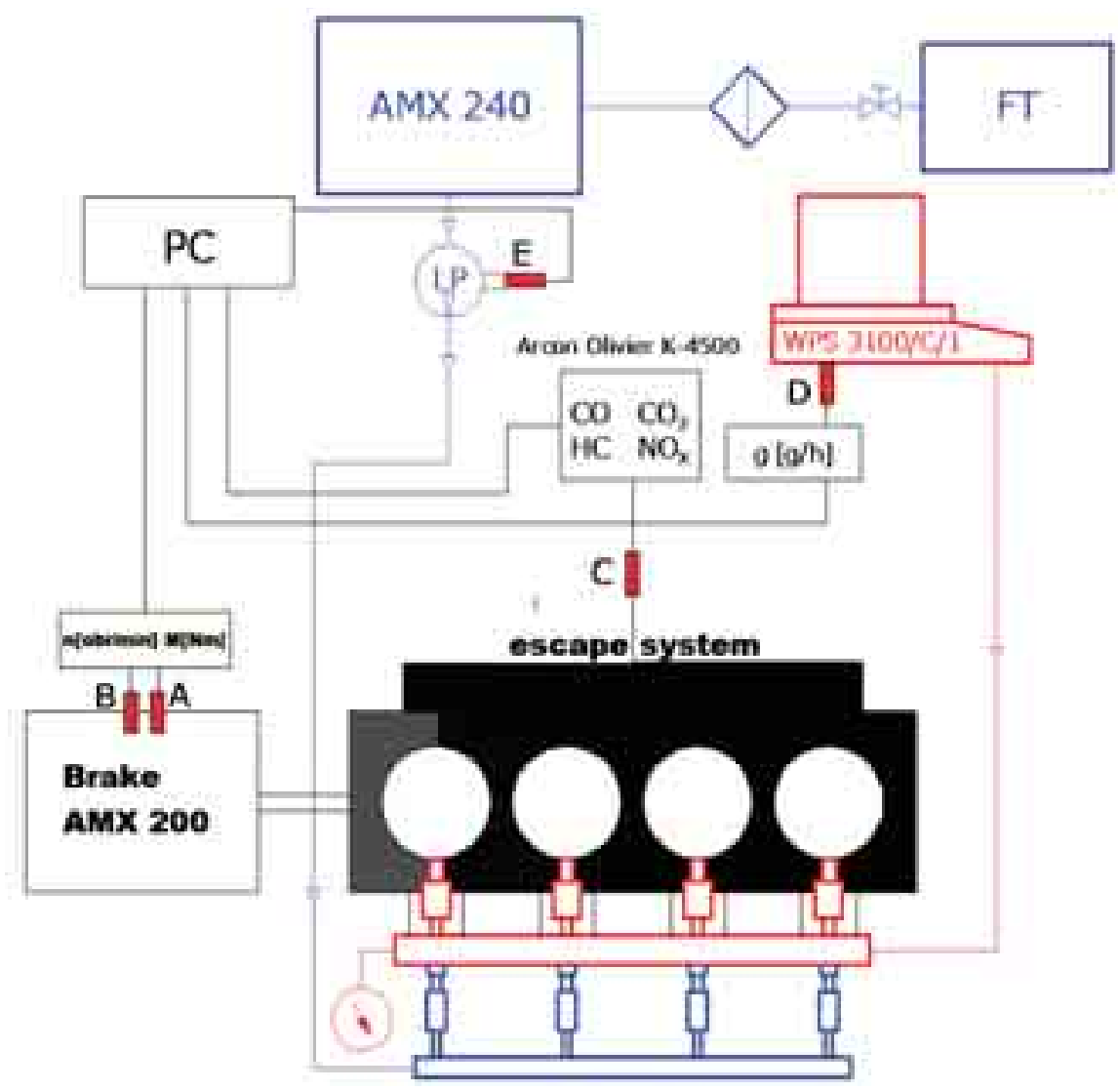

Fig. 1. Diagram of test bed (Symbols: A - measurement of rotational speed, B - measurement of rotational moment, $C$ - measurement of coefficient of air surplus, and toxic components of the exhaust fumes, $D$-measurement of mass expense of the fuel, for the ignition dose injection, E-measurement of fuel consumption of fundamental dose) 
As a result of the modifications done in the engine head based on drilling of holes under the injection systems of the ignition dose, it was necessary to do milling of cavities in piston bottom under the sleeves, in which the injection systems were located. The executed changes in the piston bottom geometry have insignificant influence on the compression value degree, and they do not affect the engine's working parameters. The location of the injection systems of ignition dose and the fundamental injection, as well as the global cross-section of the power supply system of the two-cycle engine are shown on Fig. 2. Fig. 3 presents the diagram of the power supply system.

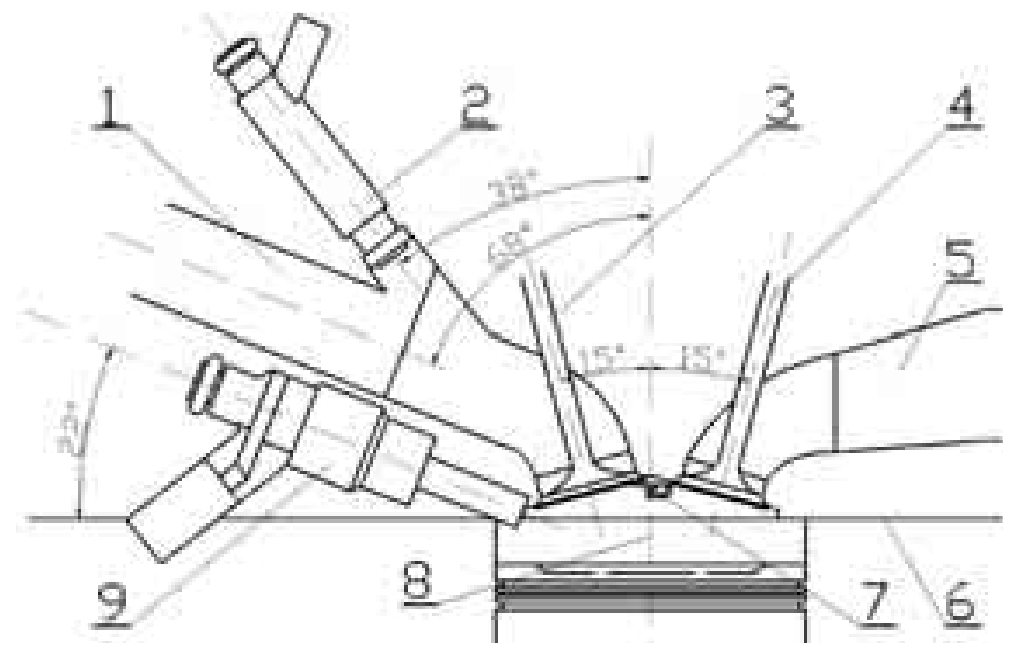

Fig. 2. Diagram of the location of the elements of the power supply systems for two-cycle engine 1 -approach duct, 2 - injection system of the fundamental dose (petrol), 3 - approach valve, 4 - escape valve, 5 - escape duct, 6 - surface of mutual location of head and block of engine, 7 - spark plug, 8 - axis of cylinder symmetry, 9 - ignition dose injection system

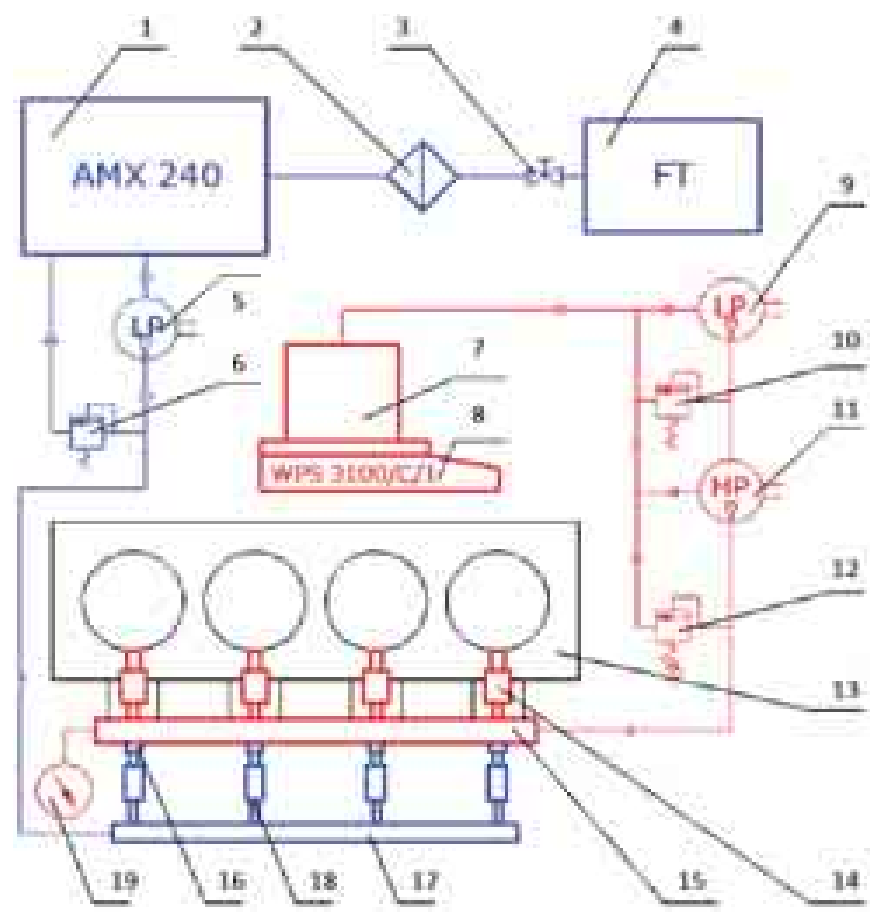

Fig. 3. Power supply system of the test engine (1-gravimetric fuels gauge, 2 - fuels filter, 3 - cutting off valve, 4 - fuels tank for MPI system, 5 - pomp of fuel of petrol injection, 6-controller of pressure of petrol injection, 7 - fuels tank for the ignition dose system, 8 - laboratory scales, 9 - powering pomp system of ignition dose, 10 - controller of low pressure of circuit of ignition dose, 11 - pomp of high pressure, 12 - pressure's controller of injection of ignition dose, 13 - test engine, 14 - ignition dose injection system, 15 - fuel rail of injection ignition dose systems, 16 - approach duct, 17 - fuel rail of MPI system, 18 - petrol injection system for MPI system, 19 - pressure manometer of the ignition dose injection) 


\section{Experimental research}

The experimental research of the two-cycle engine working with the spark ignition and the combustion initiated by means of the injection of the fuel ignition dose, aimed essentially at assigning the load characteristics, as well as the comparison of the engine performance and its general efficiency at the chosen point of work area when changing the mixture ignition method from the spark one to the one initiated by means of the pilot dose autoignition. For the purpose of assigning the load characteristics for the engine on the test stand, working in the system of the ignition fuel injection, the following initial parameters were set:

- the rotational speed of the engine $2000[\mathrm{rpm}]$,

- the pressure in the approach collector

$0.132[\mathrm{MPa}]$,

- the angle of the ignition dose injection beginning

$28\left[{ }^{\circ} \mathrm{CA}\right]$ before GMP,

- the pressure of the ignition dose injection

$15[\mathrm{MPa}]$.

During the executed research, both the fundamental dose sizes and the injected ignition dose were variable. The purpose of this diversity, is determining the best proportions of the injected fuel doses, to obtain the best performance of the test engine. Fig. 4 shows the size of the fuel doses at the consecutive measuring points concerning the values of the engine's rotational moment, broken down into the mass of fundamental and ignition dose.

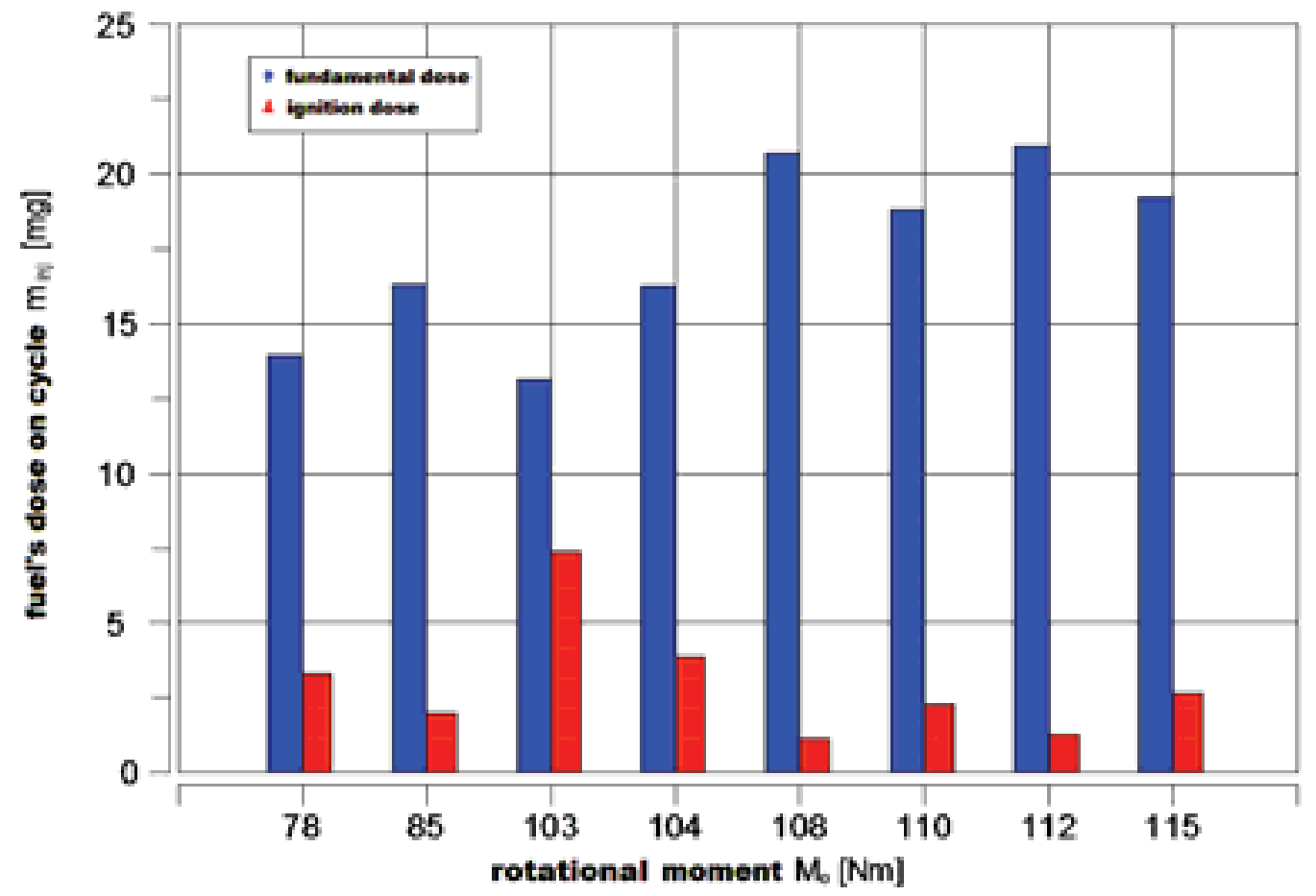

Fig. 4. Fuel doses size in the successive points of load characteristics of the engine working with the combustion initiation from the ignition dose at $n=2,000$ [rpm]

The graph on Fig. 4 presents the diversified values of the fundamental and ignition dose masses. The smallest mass of the ignition injection dose which is needed to initiate the combustion is applied for the rotational moment value of $108[\mathrm{Nm}]$ and is equal to $1.34[\mathrm{mg}]$ per cycle, which is equal to about $6.5 \%$ of the total mass of the fuel consumed by the engine per one cycle of work. At that point, of the engine work the fundamental dose was equal to 20.47 [mg]. The biggest mass of ignition dose with the value of 7.16 [mg] concerns the engine work point of the rotational moment of $103[\mathrm{Nm}]$. Afterwards, the comparison of the test engine performance was executed, working in the mode of spark ignition and also the ignition dose, and the results of the rotational moment and the effective power obtained by the two-cycle engine, were presented on Fig. 5. 


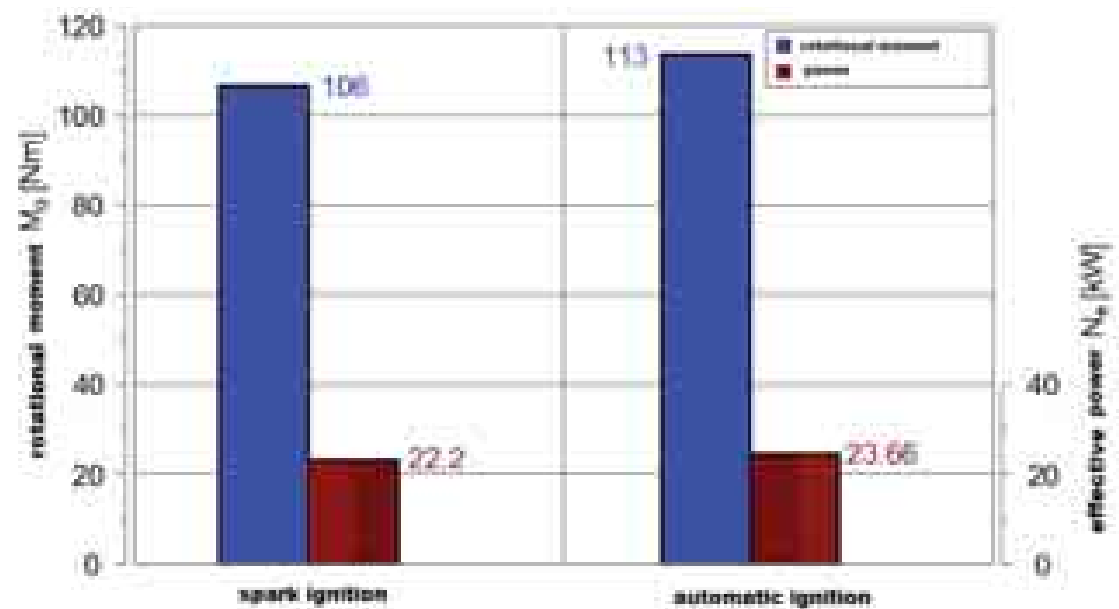

Fig. 5. Comparative diagram of the rotational moment and the effective power of the test engine working with the spark ignition and with the mixture combustion initiated from the ignition dose at $n=2000$ [rpm]

The decrease in fuel consumption was obtained when the engine worked in the mode of the ignition dose of $8.74 \%$ in relation to the value obtained for these same work parameters with the combustion initiated from the spark ignition. The executed analysis of the two-cycle engine's general efficiency, confirms its increase as a result of the application of the power supply system with the injection of ignition dose, which is presented on Fig.6. As a result of the initiation of the load combustion from the ignition dose for the rotational speed $n=2000[\mathrm{rpm}]$ the engine's general efficiency was improved by the value of 0.039 , which means the relative increment of $11.1 \%$ in comparison with an engine working in the work mode of spark ignition.

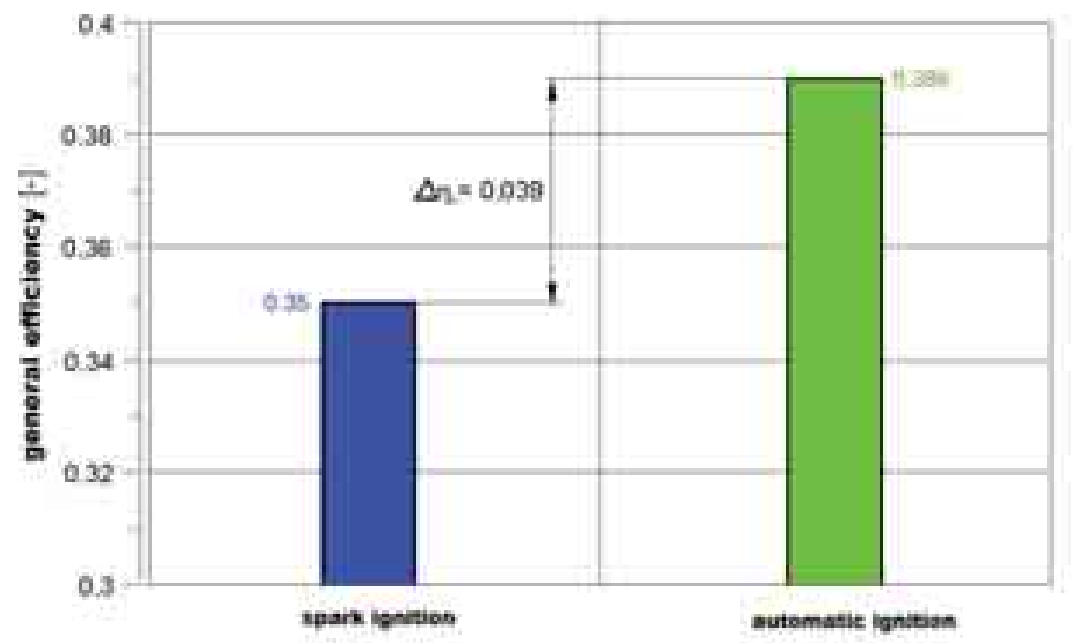

Fig.6. Comparison of general efficiency obtained by the engine working with the spark ignition and with the combustion initiated from ignition dose at $n=2000$ [rpm]

\section{Comparison of the general efficiency of the two-cycle engine working in two modes}

For the purpose of proving the legitimacy of the application of the system of the ignition dose direct injection, the analysis of parameters for a two-cycle engine work was executed, showing the increase of the general efficiency of the applied power supply system in relation to the conventional spark ignition system. For that purpose, the comparison was executed of the general efficiency obtained by the test engine as a result of the computer simulation, as well as the test-stand research of the engine working in two modes, and on this basis the legitimacy of that type of constructional solution was proved.

Figure 7 presents a comparison of the individual fuel consumption and the general efficiency of the engine working in two modes in the crank angle function determined based on the test-stand research. 


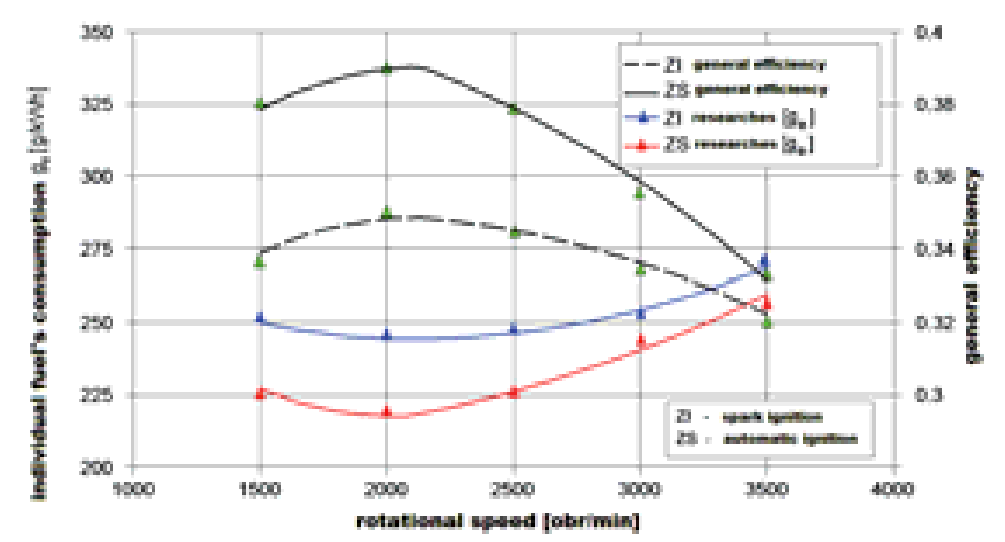

Fig.7. Comparison of the general efficiency of the engine working in two modes in the crank angle function determined based on the test-stand research

The explicit conclusion of the calculations executed during the research is that, in case of the combustion initiated from the ignition dose in the total range of the rotational speed, the decrease of the individual fuel combustion occurs, which causes a relative increase of the general engine efficiency in the total range of rotational speed. For the purpose of the detailed determining the benefits of the application of the direct ignition dose injection system, the decrease of fuel consumption and the increase of the general efficiency were presented on Fig. 8-9, which was obtained on the basis of the test-stand research, taking into account the curves of value changeability in the total range of rotational speed.

Figure 8 presents the course of the decrease of fuel consumption for the ignition dose, determined in relation to the work mode of a spark ignition, obtained based on test-stand research as well as the curve showing the course value changeability of fuel consumption. As a result of the executed test-stand research, the maximal difference of the individual fuel consumption in favour of the work mode with the ignition dose was obtained, which concerns 2,000 [rpm] and equals $25.5[\mathrm{~g} / \mathrm{kWh}]$. The difference in fuel consumption between the result obtained by means of the $K I V A 3 V$ program and the test-stand research for the ignition dose is equal to 1.5 [g/kWh], which gives the difference of $5.8 \%$.

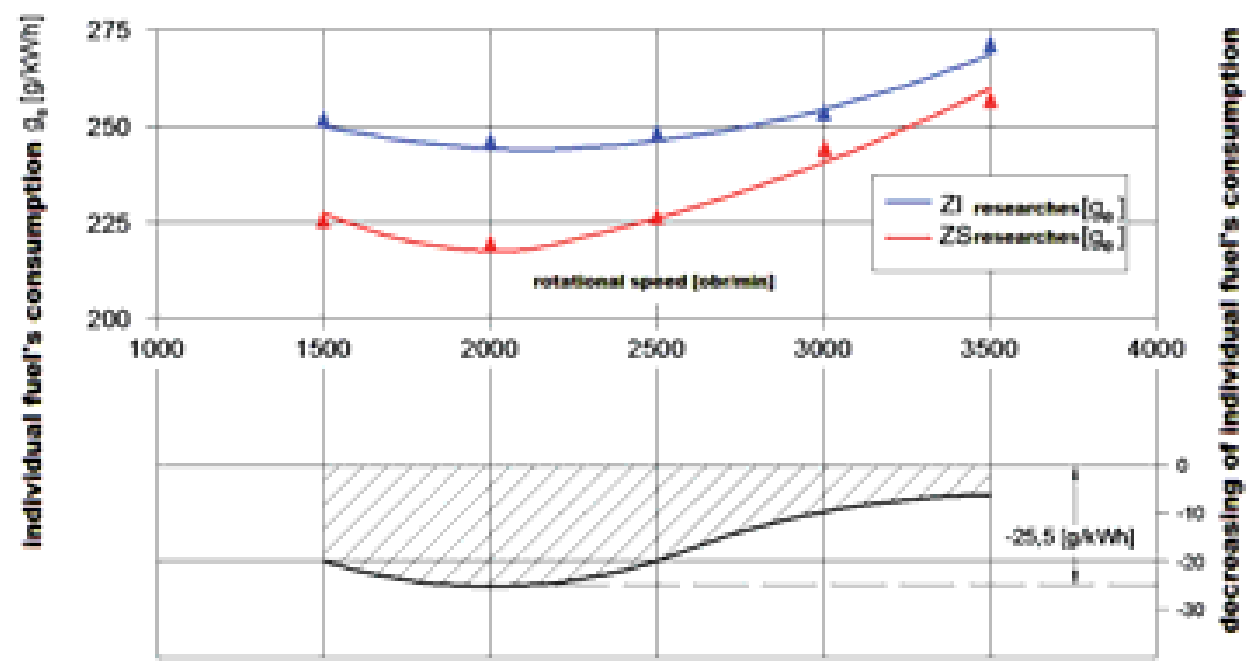

Fig.8. The course of the decrease of fuel consumption for the ignition dose, determined in relation to the work mode of a spark ignition, obtained based on test-stand research

Figure 9 presents the course of the increase of the general engine efficiency for the ignition dose determined in relation to the work mode of the spark ignition, set based on the test-stand research. 


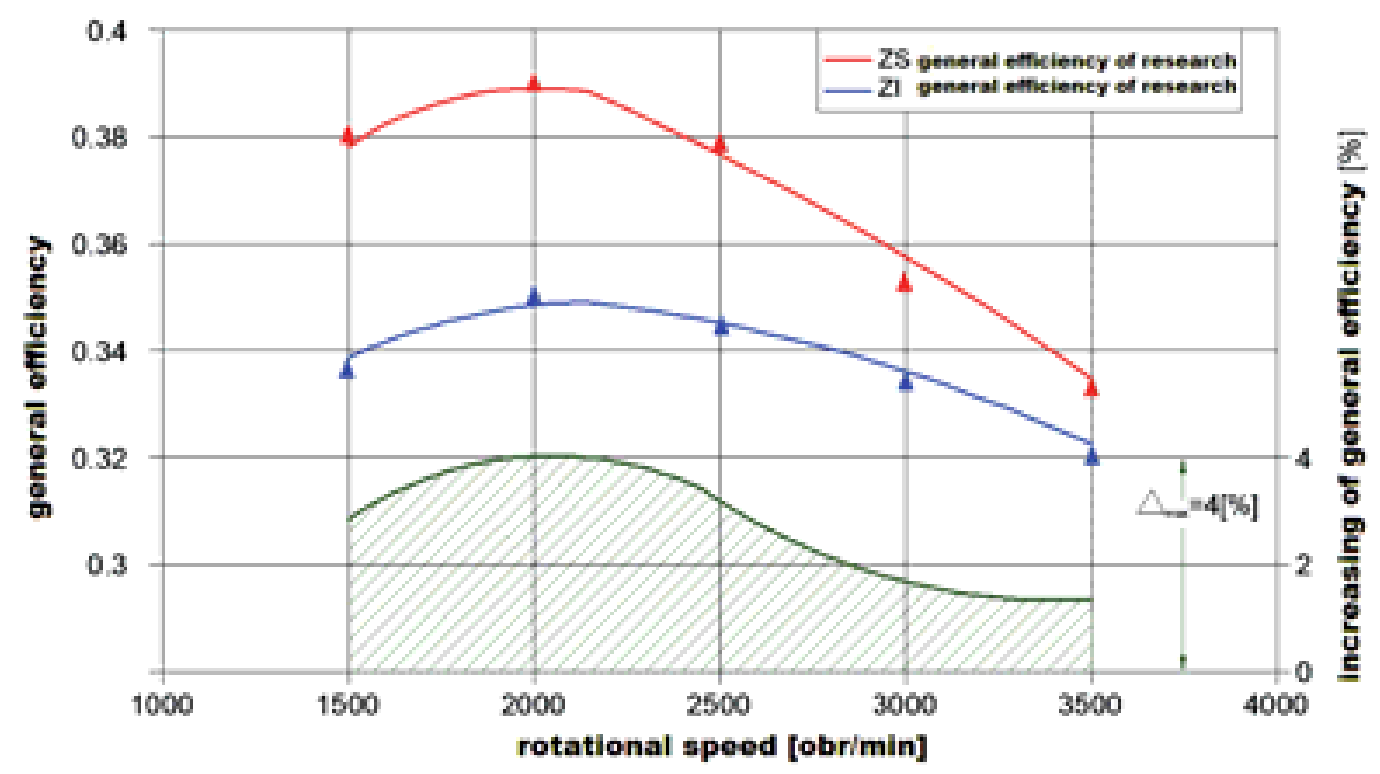

Fig. 9. The course of the increase of the general engine efficiency for the ignition dose determined in relation to the work mode of the spark ignition, set based on test-stand research

From the courses of individual fuel consumption presented on Fig. 8, the curves of the general efficiency were executed, which were presented on Fig. 9. The maximal value of the general efficiency occurs at the rotational speed of 2,200 [rpm] and is equal to about $39 \%$ for the work mode with an automatic ignition. The increase in the general efficiency for the initiation of the combustion process from the ignition dose in relation to the spark ignition was determined to be $4 \%$ and is the biggest value in the total analysed range of the rotational speed. The applied system of the direct injection of the ignition dose, causing the autoignition of the mixture in the cylinder, allows the obtainment in the range 1500-2500 [rpm] of the high general efficiency above $38 \%$.

\section{Summary of the experimental research}

Based on the analysis of the results of the executed test-stand research, the conclusion is as follows:

1. It is possible to improve the work of the engine in which the combustion is initiated by the injection of the ignition fuel dose of a relatively small mass of about $5-8 \%$ of the mass of the fuel on working cycle.

2. In the chosen points of the work area, the transition to the mode of the combustion initiated by means of the ignition injection is characterized with the obtainment of a distinctly bigger general efficiency at a simultaneous improvement of the engine performance.

3. A large increase in the general efficiency in the case of application of the work mode of the engine with the combustion initiated from the ignition dose is caused by a substantial decrease in fuel consumption.

4. As a result of the executed research, the settings of the automatic system of work mode selection were obtained, enabling a soft (i.e. without fluctuation of the rotational moment and the rotational speed) transition from one system of combustion to the other; the obtained results are promising enough for the two-cycle engine to successfully find a place in traction applications.

\section{References}

[1] AEM Installation Instructions for EMS P/N30-1010, Instrukcja montażu urządzenia, Advanced Engine Management Incorporated, Hawthorne, United States of America 2003.

[2] Bosch-Hochdruck-Einspritzventil, Berufsschul Info 2003/4, Robert Bosch GmbH, Stuttgart, 
Germany 2003.

[3] Dyszy, J., Wszyscy wtryskuja, Autotechnika Motoryzacyjna Nr 1-2/2010, s. 10-15, MotoMedia Forum Sp. z o.o., Warszawa 2010.

[4] Lambda Sensor LSU 4.2, Karta informacyjna produktu, Bosch Engineering GmbH, Abstatt Germany 2010.

[5] Lambda Sensor LSU 4.9, Karta informacyjna produktu, Bosch Engineering GmbH, Abstatt, Germany 2010.

[6] Yaris. New Car Features. Supplement. May 2002, Instrukcja serwisowa, Toyota Motor Corporation, Japan 2002. 